\title{
Tetrabenzporphyrin Complexes of Iron, Palladium and Platinum
}

\author{
A. VOGLER, H. KUNKELY and B. RETHWISCH \\ Institut für Chemie, Universität Regensburg, D-8400 Regensburg, F.R.G. \\ Received September 20, 1979
}

The syntheses and absorption spectra of $\mathrm{Fe}(\mathrm{II})$ $T B P($ pyridine $), 2 d(I I) T B P$, and $P t(I I) T B P(T B P=$ Tetrabenzporphyrin) are reported. The emission spectra of PdTBP and PtTBP were measured. Both complexes exhibit only phosphorescence from the lowest triplet of TBP. The Fe complex was oxidized to the cation $\left[\mathrm{FeTBP} \text { (pyridine) }{ }_{2}\right]^{+}$which was characterized by its absorption and ESR spectrum. The emission spectra of Pd and PtTBP as well as the spectral properties of $\left[\mathrm{FeTBP}(\text { pyridine })_{2}\right]^{+}$are discussed.

\section{Introduction}

Metalloporphyrins play a central role in many important biological processes $[1,2]$. These include photosynthesis, redox reactions, and oxygen transport and storage. A particularly useful approach to learn more about these systems involves the substitution of the naturally occuring metals by others $[3,4]$. The accompanying change of chemical and physical properties helps to clarify the role of the natural metalloporphyrines. A related approach is the modification of the porphyrin ligand. Tetrabenzporphyrin (TBP) appears to be a good choice for such investigations because, due to the extended $\pi$ electron system, it deviates from natural porphyrins to the largest extent with respect to redox [5] and optical properties $[6,7]$. Metal complexes of TBP were first

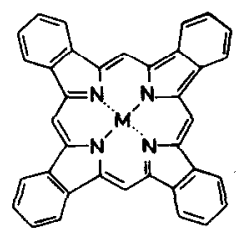

synthesized by Helberger et al. $[8,9]$ in 1938 and later by Linstead and his group $[10,11]$. The metals include $\mathrm{Mg}, \mathrm{Zn}, \mathrm{Fe}, \mathrm{Cu}$ and $\mathrm{Mn}$. Later $\mathrm{Cd}, \mathrm{V}$, and $\mathrm{Pd}$ complexes of TBP were mentioned [12]. Although the initial spectroscopic studies showed that TBP complexes have unique optical properties [13], the investigation of these compounds was hampered by the difficulties encountered in the preparation of TBP
[6]. Only recently was ZnTBP prepared in high yield using a very simple template synthesis [14]. TBP proved to have very interesting redox properties [5].

We report mainly on the preparation of TBP complexes of $\mathrm{Fe}, \mathrm{Pd}$, and $\mathrm{Pt}$. The description of the iron complex includes some observations on the redox behavior which is of interest with regard to the biological function of cytochromes. PdTBP and PtTBP were prepared in order to obtain some basic information on the optical properties of these complexes. The luminescence behavior, in particular, may give more insight into excited state processes of metalloporphyrins [7].

\section{Experimental}

\section{Materials}

Dipyridinetetrabenzporphyriniron(II)

To a solution of $10 \mathrm{~g}$ acetophenone-2-carboxylic acid (Aldrich) and $10 \mathrm{~g}$ ammonium acetate in $40 \mathrm{ml}$ conc. ammonia in a 11 flask were added $6 \mathrm{~g}$ iron powder and $4 \mathrm{~g}$ of molecular sieve (4 $\AA$, Merck). The mixture was heated rapidly under a stream of nitrogen. Rapid heating was achieved by transferring the flask and contents to a fully pre-heated mantle. The temperature of the reaction mixture reached about $400{ }^{\circ} \mathrm{C}$. After about $80 \mathrm{~min}$ the residue was allowed to cool with continued passage of $\mathrm{N}_{2}$, washed with $\mathrm{CHCl}_{3}$, and then extracted several times with hot pyridine. The combined extracts were cooled, added to ether, and filtered after $30 \mathrm{~min}$. The darkgreen filtrate was concentrated to $15 \mathrm{ml}$ in a rotating evaporator. Upon addition of $30 \mathrm{ml}$ ether the solution was chromatographed on $\mathrm{Al}_{2} \mathrm{O}_{3}$ (neutral), using a $20 \%$ solution of pyridine in ether as eluent.

The yellow-green fraction eluting first was discarded. The remaining eluate was concentrated to 5 $\mathrm{ml}$ by evaporation, treated with $50 \mathrm{ml}$ methanol, and then allowed to stand overnight at $-20^{\circ} \mathrm{C}$. The precipitate which formed was filtered off, washed with methanol and petrolether, and finally dried. The yield of almost black crystals of FeTBP(pyridine) was $1.3 \mathrm{~g} \mathrm{(15 \% ).} \mathrm{Anal.} \mathrm{Caled:} \mathrm{C,} \mathrm{76.46;} \mathrm{H,} \mathrm{4.18;} \mathrm{N,}$ 
11.63; Fe 7.73. Found: C, 76.33; H, 4.24; N, 11.57; $\mathrm{Fe}, 7.86$.

The absorption spectrum of FeTBP(pyridine) ${ }_{2}$ in pyridine/ether (1:5) shows band maxima at $596 \mathrm{~nm}$ $(\epsilon=72000), 573 \mathrm{~nm}(18500), 551 \mathrm{~nm}(12500)$, $428 \mathrm{~nm}(105000), 405 \mathrm{~nm}(48000)$, and $383 \mathrm{~nm}$ (73000). These bands agree fairly well with the spectrum reported by Linstead [10].

\section{Free-base tetrabenzporphyrin}

Crude ZnTBP [14] was not purified by chromatography but directly demetallated with concentrated sulfuric acid according to the method of Helberger [8]. The procedure applied by Linstead $[10,11]$ does not seem to offer any advantage. $2 \mathrm{~g}$ crude $\mathrm{ZnTBP}$ was stirred in $200 \mathrm{ml}$ conc. $\mathrm{H}_{2} \mathrm{SO}_{4}$ at $40{ }^{\circ} \mathrm{C}$ for 30 minutes. The resulting greenish-brown solution was filtered. The filtrate was poured on $400 \mathrm{~g}$ crushed ice. After $12 \mathrm{hr}$ the suspension was centrifuged at 6000 revolutions per minute for $15 \mathrm{~min}$. The precipitate was washed with water and again centrifuged. This procedure was repeated until the water was free of acid. The precipitate was washed with acetone and dried at $80^{\circ} \mathrm{C}$. The yield of shiny dark violet crystals of $\mathrm{TBPH}_{2}$ was $1.55 \mathrm{~g}(87 \%)$.

The absorption spectrum of $\mathrm{TBPH}_{2}$ agreed well with that reported in the literature [15].

\section{Tetrabenzporphyrinpalladium(II)}

$0.67 \mathrm{~g} \mathrm{TBPH}_{2}$ and $1.25 \mathrm{~g} \mathrm{PdCl}_{2}$ were dissolved in $85 \mathrm{ml}$ dimethylformamide and stirred at $115^{\circ} \mathrm{C}$ for 3 to 4 days. The reaction is completed when the absorption spectrum of $\mathrm{TBPH}_{2}$ has been changed to that of PdTBP (see below). After evaporation the blue-black powder was dried and extracted with methanol overnight to remove excess $\mathrm{PdCl}_{2}$. Additional impurities were removed by sublimation at $280^{\circ} \mathrm{C}$ and $6 \times 10^{-3}$ Torr. The residue was dissolved in DMF. The volume was reduced by evaporation. After precipitation with methanol the resulting suspension was kept overnight at $-20{ }^{\circ} \mathrm{C}$. The blueblack crystals of PdTBP were filtrated and dried at $80{ }^{\circ} \mathrm{C}$ (yield $0.5 \mathrm{~g}, 62 \%$ ). Anal. Calcd: C, 70.30; N, 9.10; H, 3.28; Pd, 17.32. Found: C, 69.89; N, 9.06; H, 3.38; Pd, 17.67.

\section{Tetrabenzporphyrinplatinum(II)}

$1 \mathrm{~g}$ platinum black was stirred in $10 \mathrm{ml} \mathrm{Br}{ }_{2}$ for $4 \mathrm{hr}$ at room temperature. After addition of $5 \mathrm{ml}$ ethanol, a solution of $0.3 \mathrm{~g} \mathrm{TBPH}{ }_{2}$ in $75 \mathrm{ml}$ dimethylformamide was added. This mixture was stirred at $110^{\circ} \mathrm{C}$ for about one day until the spectrum indicated that $\mathrm{TBPH}_{2}$ (absorption at $663 \mathrm{~nm}$ ) was consumed. After evaporation the residue was extracted with methanol for $24 \mathrm{hr}$ to remove an excess of $\mathrm{PtBr}_{2}$. The product was first dried at $150{ }^{\circ} \mathrm{C}$ and finally at $220^{\circ} \mathrm{C}$ in vacuum $\left(6 \times 10^{-3}\right.$ Torr $)$, to remove volatile impurities. The residue consisted of shiny black-green crystals of PtTBP (yield $0.3 \mathrm{~g}$, 73\%). Anal. Calcd: C, 61.40; N, 7.96; H, 2.86; Pt, 27.78. Found: C, 61.11; N, 8.09; H, 3.74; Pt, 27.06.

\section{Spectra}

Visible and ultraviolet spectra were measured with a Super Scan 3 spectrophotometer (Varian/ Techtron). Solvents were spectrograde (Uvasole, Merck). Emission spectra were recorded on a modified Aminco spektrofluorometer SPF, equipped with a red-sensitive photomultiplier $R 666 \mathrm{~S}$ (Hamamatsu). Additional cut-off filters were used to eliminate exciting light at the detector. ESR-spectra were measured with a Bruker ER 420 spectrometer (microwave frequency $9.5 \mathrm{GHz}$ ).

\section{Results and Discussion}

\section{Dipyridinetetrabenzporphyrin}

For the preparation of FeTBP the best results were not obtained by the metalation of the free base $\mathrm{TBPH}_{2}$ [16] (see below) but by a direct modified template synthesis which has been successful for the preparation of $\mathrm{ZnTBP}$ [14]. Metallic iron as a powder reacts directly with commerically available acetophenone-2-carboxylic acid and ammonia at higher temperatures according to the stoichiometry.

$$
3 \bigcirc_{\mathrm{COOH}}^{\mathrm{COCH}_{3}}+4 \mathrm{NH}_{3}+\mathrm{Fe}+\mathrm{FeTBP}+12 \mathrm{H}_{2} \mathrm{O}
$$

FeTBP was not further investigated. Upon dissolution in pyridine, FeTBP(pyridine) ${ }_{2}$ was obtained.

In solutions of methanol/pyridine (5:1) or ether/ pyridine (5:1) FeTBP(py) $)_{2}$ was oxidized by a variety of agents such as $\mathrm{Cl}_{2}, \mathrm{Br}_{2}, \mathrm{I}_{2}$ or chloramine $\mathrm{T}$. This oxidation is reversible. Upon reduction with $\mathrm{NaBH}_{4}$ the oxidized complex was completely converted back to $\operatorname{FeTBP}(p y)_{2}$. The spectral changes accompanying this oxidation are shown in Fig. 1. The Soret band, although shifted and broadened, is still preserved while in the longer wavelength region the $\alpha$-band of FeTBP(py $)_{2}$ almost disappears. Some less pronounced new absorptions occur. The spectral pattern of the oxidized complex is similar, although not identical, to that of low-spin hexacoordinated $\mathrm{Fe}$ (III) porphyrins [7]. The oxidation product may then be formulated as $\left[\mathrm{Fe}(\mathrm{III}) \mathrm{TBP}(\mathrm{py})_{2}\right]^{+}$. This is supported by the spectrum of $\left[\mathrm{Zn}\left(\mathrm{TBP}^{+}\right)\right]^{\oplus}[5]$ and $\left[\mathrm{Fe}(\mathrm{II})\left(\mathrm{TBP}^{+}\right)(\mathrm{py}) \mathrm{CO}\right]^{+}{ }^{-17]}$ which are clearly different from that of $\left[\mathrm{FeTBP}(p y)_{2}\right]^{+}$. In the oxidation of $\mathrm{Fe}(\mathrm{II}) \mathrm{TBP}(\mathrm{py}) \mathrm{CO}$, the TBP ligand is oxidized to the TBP $\pi$ radical cation and the metal is not oxidized. This difference in oxidation behavior between the carbonyl and dipyridine complex can be explained by the larger stabilization of $\mathrm{Fe}(\mathrm{II})$ by $\mathrm{CO}$ 


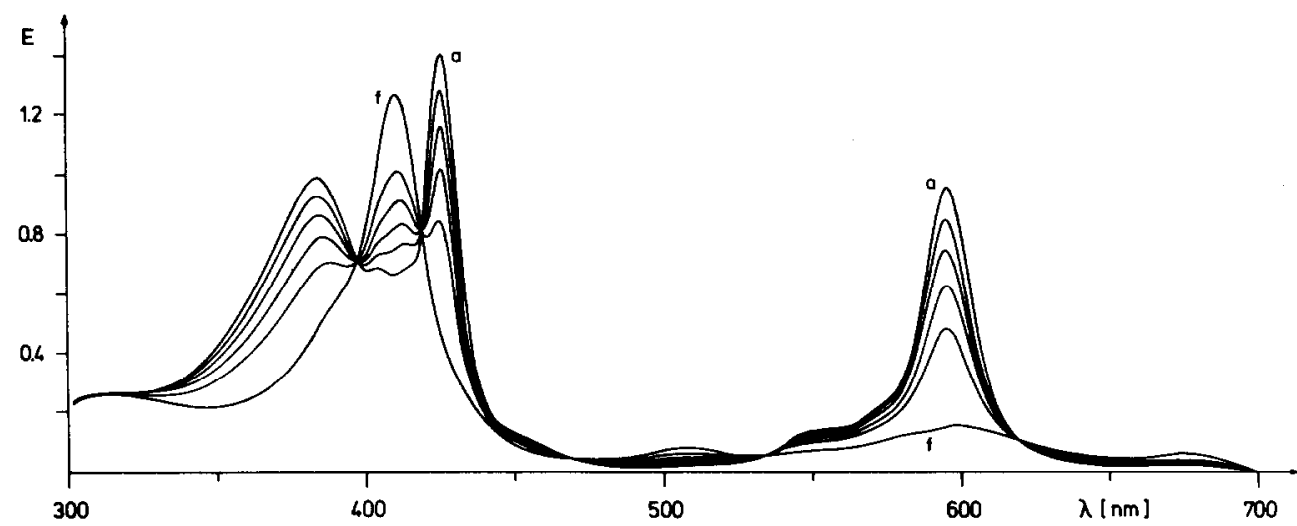

Fig. 1. Spectral changes during the oxidation of $1.34 \times 10^{-5} \mathrm{M}$ FeTBP(pyridine) $)_{2}$ by iodine in pyridine/methanol (1:10); $1 \mathrm{~cm}$ cell.

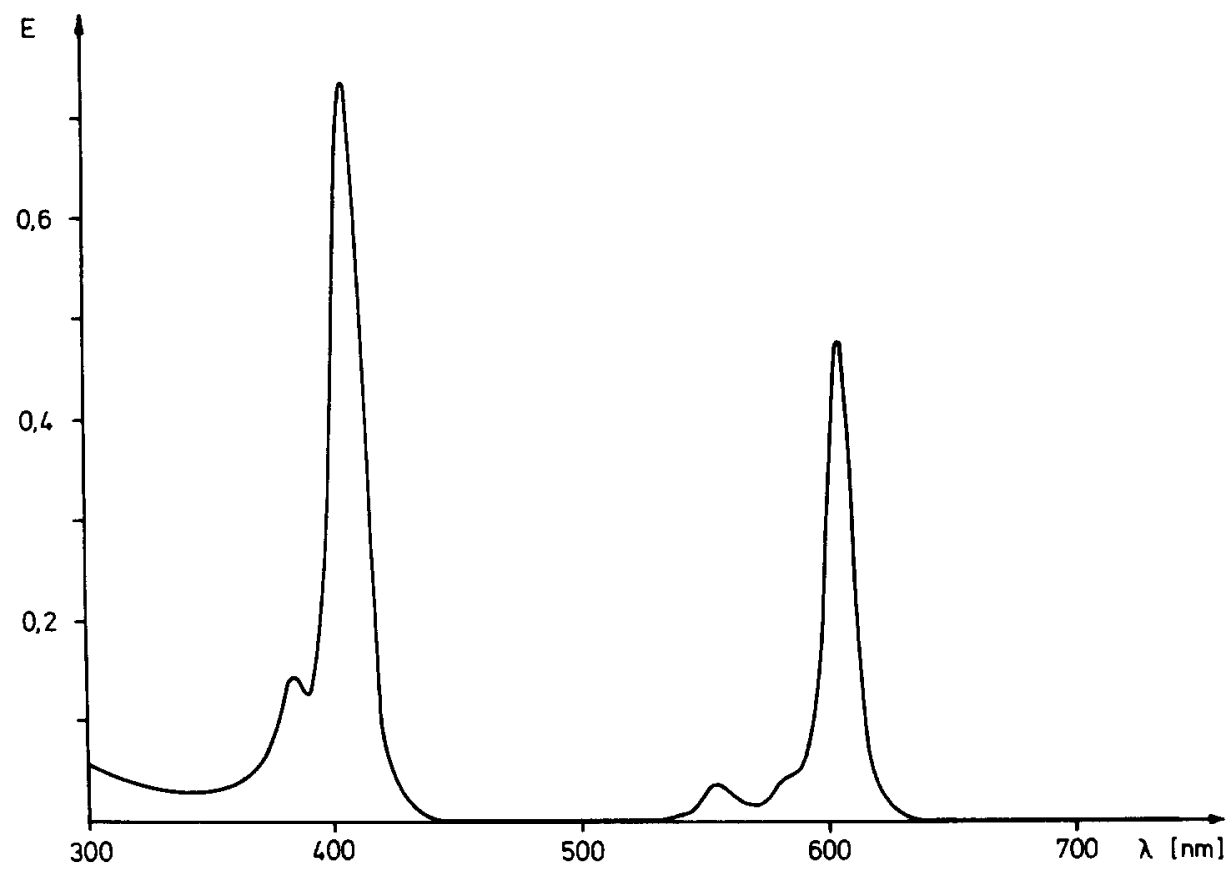

Fig. 2. Absorption spectrum of $4.1 \times 10^{-6} M$ PdTBP in DMF; $1 \mathrm{~cm}$ cell.

versus pyridine [17]. While in the carbonyl complex $\mathrm{Fe}$ (II) would be oxidized at higher potentials than TBP, $\mathrm{Fe}$ (II) is oxidized at lower potentials in the dipyridine complex.

On the other hand, ESR spectra of [FeTBP$\left.(\mathrm{pyr})_{2}\right]^{+}$, which were obtained at temperatures between 45 and $77 \mathrm{~K}$, do not indicate the formation of $\mathrm{Fe}(\mathrm{III})$. In contrast to ESR spectra of $\mathrm{Fe}$ (III) porphyrins [18] the spectrum of $\left[\mathrm{FeTBP}(p y)_{2}\right]^{+}$shows only a singlet with $\mathrm{g}=2.0018$ and a width of $3.75 \mathrm{G}$. This is similar to the spectra of $[\mathrm{ZnTBP}]^{+}[5]$ and $\left[\mathrm{Fe}(\mathrm{II})\left(\mathrm{TBP}^{+}\right)(\mathrm{py})(\mathrm{CO})\right]^{+}$[17] where it has been shown that TBP was oxidized. Consequently the oxidation product of $\mathrm{FeTBP}(\mathrm{py})_{2}$ should be formulated as $\left[\mathrm{Fe}(\mathrm{II})\left(\mathrm{TBP}^{+}\right)(\mathrm{py})_{2}\right]^{+}$.
Although these results on the optical and ESR spectra of $\left[\mathrm{FeTBP}(\mathrm{py})_{2}\right]^{+}$seem to be contradictory and merit further investigation, a tentative explanation may be given. If the energy of $\left[\mathrm{Fe}(\mathrm{II})\left(\mathrm{TBP}^{+}\right)\right.$$\left.(\mathrm{py})_{2}\right]^{+}$is only slightly lower than that of $[\mathrm{Fe}(\mathrm{III})$ $\left.\operatorname{TBP}(\mathrm{py})_{2}\right]^{+}$, (which is then actually a charge transfer excited state of the former) a temperature dependent equilibrium between both 'oxidation state isomers' [19] may exist. At low temperatures [Fe( $\left.\mathrm{TBP}^{+}\right)$$\left.(\mathrm{py})_{2}\right]^{+}$may prevail consistent with the ESR spectra. At room temperature the CT state may be populated in accordance with the optical spectrum. Since the ESR signal disappears above $77 \mathrm{~K}$ careful measurements of the temperature dependence of the absorption spectrum may give a definite answer. First 


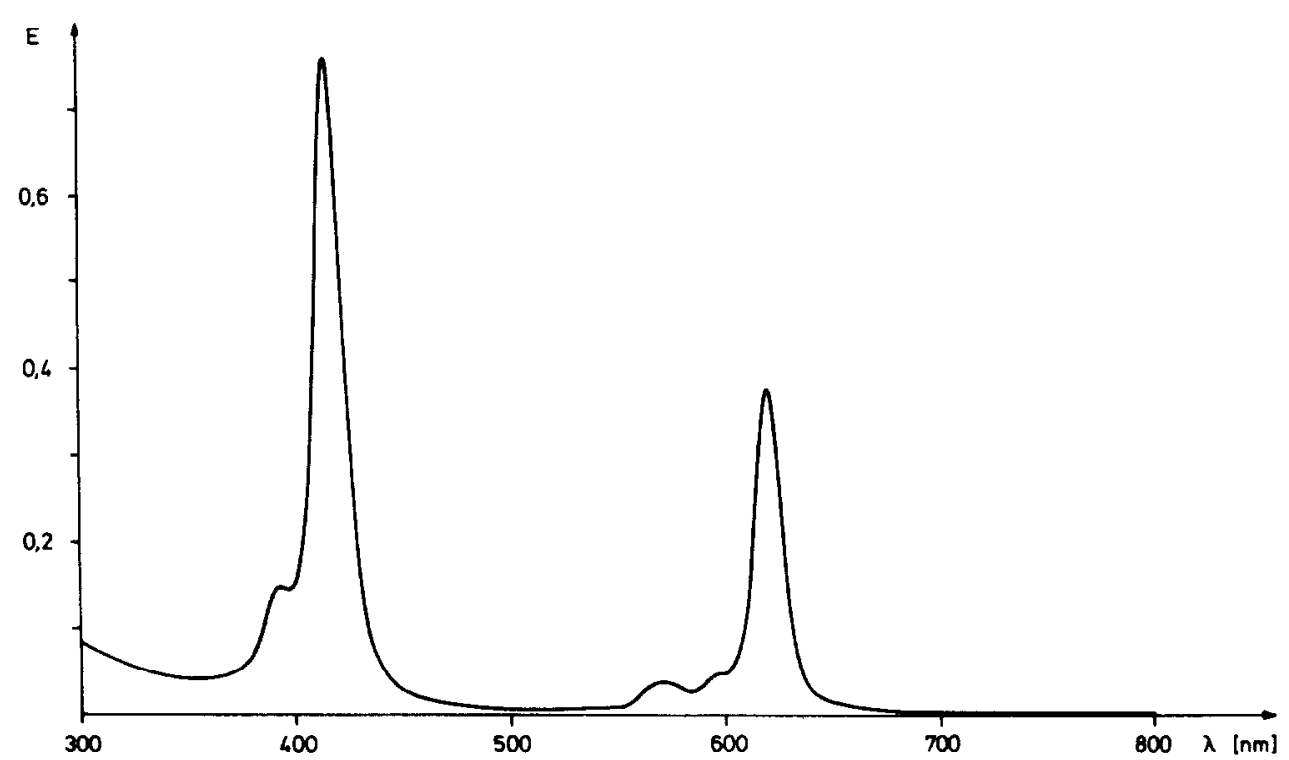

Fig. 3. Absorption spectrum of $3.56 \times 10^{-6} M$ PtTBP in DMF; $1 \mathrm{~cm}$ cell.

TABLE I. Absorption and Emission Maxima (nm).

\begin{tabular}{|c|c|c|c|c|c|c|c|}
\hline \multirow[t]{3}{*}{ Compound } & \multicolumn{5}{|c|}{ Absorption (e); in DMF } & \multicolumn{2}{|c|}{ Emission at $77 \mathrm{~K}, \lambda_{\text {exc. }} 406 \mathrm{~nm}$} \\
\hline & \multicolumn{2}{|l|}{ B } & \multicolumn{3}{|l|}{$Q$} & \multirow[t]{2}{*}{ Solvent } & \multirow[t]{2}{*}{$T_{1}(0,0)$} \\
\hline & Soret $(0,0)$ & other & $\alpha(0,0)$ & others & & & \\
\hline PdTBP & $\begin{array}{l}407 \\
(179000)\end{array}$ & $\begin{array}{l}384 \\
(39300)\end{array}$ & $\begin{array}{l}607 \\
(105000)\end{array}$ & $\begin{array}{l}584 \\
(8700)\end{array}$ & $\begin{array}{l}558 \\
(6500)\end{array}$ & DMF & 762 \\
\hline РtTBP & $\begin{array}{l}416 \\
(213400)\end{array}$ & $\begin{array}{l}393 \\
(45600)\end{array}$ & $\begin{array}{l}621 \\
(103200)\end{array}$ & $\begin{array}{l}598 \\
(12900)\end{array}$ & $\begin{array}{l}571 \\
(9400)\end{array}$ & $\begin{array}{l}\text { DMSO/Ethanol } \\
(1: 1)\end{array}$ & 785 \\
\hline
\end{tabular}

attempts to solve this problem failed due to inappropriate equipment.

\section{Tetrabenzporphyrinpalladium(II) and Platinum(II)}

The synthesis of PdTBP and PtTBP was achieved by the metalation of free base $\mathrm{TBPH}_{2}$ by $\mathrm{PdCl}_{2}$ and $\mathrm{PtBr}_{2}$ in dimethylformamide. The progress of the reaction was conveniently followed by spectrophotometry. Attempts to metalate $\mathrm{TBPH}_{2}$ by $\mathrm{PdCl}_{4}^{2-}$ and $\mathrm{PtCl}_{4}^{2-}$ or the benzonitrile complexes $\mathrm{Pd}\left(\mathrm{C}_{6} \mathrm{H}_{5}\right.$ $\mathrm{CN})_{2} \mathrm{Cl}_{2}$ and $\mathrm{Pt}\left(\mathrm{C}_{6} \mathrm{H}_{5} \mathrm{CN}\right)_{2} \mathrm{Cl}_{2}$ [16] led to a mixture of products which could not be separated by chromatography. PdTBP and PtTBP sublimate in a vacuum at higher temperatures.

The absorption spectra of PdTBP and PtTBP (Table I) are shown in Figs. 2 and 3. While for other porphyrins the $\mathrm{Q}$ and $\mathrm{B}$ bands are blue shifted on going from $\mathrm{Pd}$ to $\mathrm{Pt}$, indicating an increase of back bonding [7], a red shift is observed for TBP. The spectrum of PtTBP seems to be almost 'regular' in the terminology of Gouterman [7], since it is very similar to that of ZnTBP [6].

ZnTBP is unique in its emission behavior because it shows a fluorescence from the second excited singlet $\left(S_{2} \rightarrow S_{0}\right)$ in addition to the phosphorescence $\left(\mathrm{T}_{1} \rightarrow \mathrm{S}_{0}\right)$ and the normal fluorescence $\left(\mathrm{S}_{1} \rightarrow \mathrm{S}_{\mathrm{o}}\right)$ $[7,12,20]$. The occurrence of this $S_{2}$ fluorescence is probably due to the large energy gap between the $S_{1}$ (or Q) state and the $S_{2}$ (or B) state. The $S_{2}$ fluorescence is very short living and was not quenched in CdTBP [12]. Cd increases intersystem crossing by its heavy atom effect. In contrast, the quantum yield of the longer living $S_{1}$ fluorescence of $\mathrm{ZnTBP}$ was greatly diminished in CdTBP. It thus was of interest to determine how transition metals with partly filled d-shells would affect the luminescence behavior of TBP. Although it has been mentioned that TBP complexes of $\mathrm{Cu}, \mathrm{V}$, and $\mathrm{Pd}$ do not emit the $\mathrm{S}_{2}$ fluorescence no further data on the absorption and emission spectra of these complexes were reported [12]. 
PdTBP and PtTBP showed a normal emission behavior of the lowest excited states $S_{1}$ and $T_{1}$, quite analogous to that of other $\mathrm{Pd}$ and $\mathrm{Pt}$ porphyrins $[7,21]$. While the $S_{1}$ fluorescence was completely absent due to rapid intersystem crossing induced by the heavy metals, the normal phosphorescence $\left(T_{1} \rightarrow\right.$ $\mathrm{S}_{\mathrm{o}}$ ) was observed at $77 \mathrm{~K}$ (Table I). It was, however, quite weak for PtTBP.

We were not able to detect any $S_{2}$ fluorescence [22] of PdTBP and PITBP in accordance with the earlier observation on PdTBP [12]. For the palladium complex it has been suggested that the $S_{2}$ fluorescence is not quenched by the heavy atom effect but by the interference of ligand field states [12], which lie between the first and second excited singlets of TBP. The large energy gap between $S_{1}$ and $S_{2}$ of TBP, which is the origin of the occurrence of the $S_{2}$ fluorescence, may thus be bridged by ligand field states. The intervening LF states could be rapidly populated from $S_{2}$ of TBP.

Besides the $\pi \pi^{*}$ absorptions of TBP other bands have not been identified in the spectra of $P d$ and PtTBP. However, it seems doubtful if ligand field excited states of these complexes do occur below $S_{2}$ of TBP. The lowest ligand field transition $\left({ }^{1} \mathrm{~A}_{1 \mathrm{~g}} \rightarrow\right.$ $\left.{ }^{3} \mathrm{E}_{\mathrm{g}},{ }^{3} \mathrm{~A}_{2 \mathrm{~g}}\right)$ of $\mathrm{Pt}\left(\mathrm{NH}_{3}\right)_{4}^{2+}$, which may be taken for comparison, gives rise to an absorption band at 286 $\mathrm{nm}$ [23]. Alternatively, the $\mathrm{S}_{2}$ fluorescence may be quenched by the presence of lower-lying charge transfer (M to $\pi^{*}$ TBP) excited states. Charge transfer (M to $\pi^{*}$ ligand) transitions of bipyridyl and $o$-phenanthroline complexes of Pt(II) do occur at reasonable low energies $[24,25]$.

\section{Acknowledgement}

Support for this research by the Deutsche Forschungsgemeinschaft and the Fonds der Chemischen Industrie is gratefully acknowledged. We thank J. Hüttermann for measurements of ESR spectra.

\section{References}

1 D. Dolphin, Ed., 'The Porphyrins', Vol. I-VII, Academic Press, New York, N.Y. (1978).

2 K. M. Smith, Ed., 'Porphyrins and Metalloporphyrins' Elsevier, Amsterdam (1975).

3 A. Vogler and H. Kunkely, Ber. Bunsenges. Phys. Chem., 80,425 (1976).

4 A. Antipas, J. W. Buchler, M. Gouterman, and P. D. Smith, J. Am. Chem. Soc., 100, 3015 (1978).

5 A. Vogler, B. Rethwisch, H. Kunkely, J. Hüttermann, and J. O. Besenhard, Angew. Chem. Int. Ed. Engl., 17, 951 (1978).

6 L. Edwards, M. Gouterman, and C. B. Rose, J. Am. Chem. Soc., 98, 7638 (1976).

7 M. Gouterman in ref. 1, Vol. III, 1978, chap. 1.

8 J. H. Helberger, A. von Rebay, and D. B. Hevér, Justus Liehigs Ann. Chem., 533, 197 (1938).

9 J. H. Helberger and D. B. Hevér, Justus Liebigs Ann. Chem., 536, 173 (1938).

10 P. A. Barrett, R. P. Linstead, F. G. Rundall, and G. A. P. Tuey, J. Chem. Soc., 1079 (1940).

11 R. P. Linstead and F. T. Weiss, J. Chem. Soc., 2975 (1950).

12 I. E. Zalesskii, V. N. Kotlo, A. N. Sevchenko, K. N. Solovev, and S. F. Shkirman, Dokl. Akad. Nauk SSSR, 210, 312 (1973). (Sov. Phys. Dokl., Engl. Transl., 18, 320 (1973).

13 See refs. 6, 7, 12 and references cited therein.

14 A. Vogler and H. Kunkely, Angew. Chem. Int. Ed. Engl., 17, 760 (1978).

15 M. Gouterman, J. Mol. Spectrosc., 6, 138 (1961).

16 For the synthesis of metalloporphyrins see J. W. Buchler in ref. 2.

17 A. Vogler, B. Rethwisch, H. Kunkely, and J. Hüttermann, Angew. Chem. Int. Ed. Engl., 17, 952 (1978).

$18 \mathrm{~J}$. Subramanian, in ref. 2.

19 G. M. Brown, F. R. Hopf, T. J. Meyer, and D. G. Whitten, J. Am. Chem. Soc., 97, 5385 (1975).

20 L. Bajema, M. Gouterman, and C. B. Rose, J. Mol. Spectrosc., 39, 421 (1971).

21 D. Eastwood and M. Gouterman, J. Mol. Spectrosc., 35, 359 (1970).

22 The $S_{2}$ fluorescence of $Z n T B P$ was close to the detection limit of our equipment. Hence a further search for the $\mathrm{S}_{2}$ emission of PdTBP and PtTBP merits further investigation.

23 W. R. Mason and H. B. Gray, J. Am. Chem. Soc., 90, 5721 (1968).

24 P. M. Gidney, R. D. Gillard, and B. T. Heaton, J. Chem. Soc. Dalton, 132 (1973).

25 D. L. Webb and L. Ancarani Rossiello, Inorg. Chem., 10, 2213 (1971). 